\title{
Eliciting Domain Knowledge Using Conceptual Metaphors to Inform Interaction Design: A Case Study from Music Interaction
}

\author{
Katie Wilkie \\ The Open University \\ Milton Keynes, MK7 6AA \\ katie.wilkie@open.ac.uk
}

\author{
Simon Holland \\ The Open University \\ Milton Keynes, MK7 6AA \\ simon.holland@open.ac.uk
}

\author{
Paul Mulholland \\ The Open University \\ Milton Keynes, MK7 6AA \\ paul.mulholland@open.ac.uk
}

\begin{abstract}
Interaction design for domains that involve complex abstractions can prove challenging. This problem is particularly acute in domains where the intricate nature of domain-specific knowledge can be difficult for even the most experienced expert to conceptualise or articulate. One promising solution to the problem of representing complex domain abstractions involves the use of conceptual metaphors. Previous applications of conceptual metaphors to abstract domains have yielded encouraging results. However, the design of appropriate methods for eliciting conceptual metaphors for the purposes of informing interaction design remains an open question. In this paper, we report on a series of studies carried out to elicit conceptual metaphors from domain experts, using music as a case study, reflecting on the benefits and drawbacks of each approach.
\end{abstract}

Conceptual Metaphor Theory, Image Schema Theory, Music Interaction, Interaction Design

\section{INTRODUCTION}

Interaction design for domains that involve complex abstractions can prove challenging. This problem is particularly acute in domains where the multifaceted nature of domain-specific knowledge can be both difficult to elicit from domain experts and complex to represent within interaction designs. Music is one such example of a complex domain. The number and diversity of domainspecific notations, terminologies, processes and concepts can prove challenging for even the most experienced musician to conceptualise or articulate in terms that are easily translatable into useful and usable interaction designs.

One promising solution to the problem of representing complex domain abstractions involves the use of conceptual metaphors. Conceptual metaphors are hypothesised metaphorical extensions of repeating patterns of prior sensorymotor experiences (known as image schemas) applied to abstract domains (Lakoff and Núñez 2000, pp. 30-45). Conceptual metaphor and image schema theories have previously been applied with

(C) The Authors. Published by

BCS Learning and Development Ltd.

Proceedings of $\mathrm{HCl} 2014$, Southport, UK some success to understanding abstract domains such as music theory (Brower 2000, Larson 19971998, Saslaw 1996, 1997-1998, Zbikowski 1997), philosophy (Lakoff and Johnson 1999) and mathematical constructs (Lakoff and Núñez 2000). These theories have also been applied successfully in a small number of cases to interaction design and user interface design and evaluation (Hurtienne and Blessing 2007, Hurtienne et al. 2008, Treglown 1999, Antle et al. 2009a, Antle et al. 2009b). However, documentation of previous elicitation work has in some cases been light and informal or more systematic but limited to domains with minimal complexity. At the same time, to the best of our knowledge, no previous work has compared the benefits and drawbacks of different approaches to eliciting domain-specific conceptual metaphors for the purposes of informing interaction designs. This paper draws on the results of three earlier studies carried out for the purposes of eliciting conceptual metaphors in the domain of music, a domain that involves challenging abstract concepts. Each of the three studies took a different, but systematically and detailed approach to the process of eliciting conceptual metaphors from domain experts. We compare the results of the studies, reflecting on the respective benefits and drawbacks of the different approaches, and their potential value in interaction design. 


\section{EMBODIED UNDERSTANDING}

The question of how conceptual models of abstract domains are developed has long interested cognitive scientists. One promising theory posits that understanding of abstract domains and concepts such as mathematics, philosophy, music, etc are grounded in constructs named image schemas (Lakoff and Núñez 2000, pp. 30-39). Image schemas are defined as repeating patterns of universal prior sensory-motor experiences such as containment, movement, forces and height and are often identified through the analysis of spoken or written text (Lakoff and Núñez 2000, pp. 30-39). As an example, consider the phrase "take the cake out of the oven". The use of the preposition "out" strongly suggests the presence of the CONTAINER image schema. This image schema is experienced throughout everyday life, for example when liquid is poured into a vessel or when walking into or out of a room (Lakoff and Johnson 2003, pp. 29-32).

The inherent structure of the CONTAINER image schema gives rise to a series of entailments that can be used to carry out spatial reasoning operations (Lakoff and Núñez 2000, pp. 30-34). Consider figure 1 below showing object $A$ residing in CONTAINER $X$. We can deduce that, as CONTAINER $X$ resides in CONTAINER $Y$, object $A$ also resides in CONTAINER $Y$. Various image schemas have been identified and catalogued representing experiences of containment, forces, height, balance, paths, cycles and attributes such as heat, light and weight (Hurtienne and Blessing 2007).

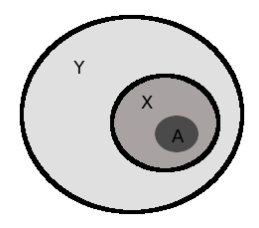

Figure 1 - Representation of the CONTAINER image schema.

Understanding of abstract concepts is posited to occur when image schemas are extended to create conceptual metaphors (Lakoff and Núñez 2000, pp. 39-45). Considering the phrase "the melody is in the key of G major", we can see that the preposition "in" indicates the presence of the CONTAINER image schema. However, in this example, the CONTAINER is a musical key, an abstract concept rather than a tangible entity. This example illustrates the use of the conceptual metaphor A KEY IS A CONTAINER FOR MELODY.

\subsection{Eliciting Image Schemas and Conceptual Metaphors}

The ability to apply image schemas to abstract domains through the creation of conceptual metaphors makes them a powerful tool for representing domain concepts. As previously noted, image schema and conceptual metaphor theories have been applied with some success to music theory (Brower 2000, Larson 1997-1998, Saslaw 1996, Zbikowski 1997). There have also been a handful of applications to user interface design and evaluation (Hurtienne and Blessing 2007, Hurtienne et al. 2008, Treglown 1999) and interaction design (Antle et al. 2009a, Antle et al. 2009b). However, information about systematic elicitation techniques has either been sparse and informal, or limited to undemanding domains, as discussed below.

In the domain of music, a number of studies have focussed on eliciting image schemas and conceptual metaphors from music theory texts (e.g. Saslaw 1996, 1997-1998). However, it is unclear the extent to which working musicians conceptualise their daily activities in anything like these terms. Other studies in the domain of music have focused informally on anecdotal utterances (e.g. Larson 1997-1998), but with minimal discussion of systematic elicitation techniques.

In an early example of deriving image schemas and conceptual metaphors from dialogue transcriptions and descriptions of working practices, Treglown (1999) explored how image schemas and conceptual metaphors can be mapped to aspects of the interaction model for his file management and operating system. Taking a more systematic approach to the elicitation process, Hurtienne et al. (2008) investigated the use of image schemas as a "meta-language" for analysis and design. Undertaking interviews, field observations and documentation reviews, they were able to identify a number of image schemas that underlay both relevant business processes and their treatment in an existing user interface for invoice processing. Thus, they were able to reframe business and user requirements for a redesigned version of the system. Finally, Antle et al. (2009b) elicited embodied metaphors to assist in interaction design for manipulating concepts such as pitch and volume through movement studies, pilot studies and reviews of relevant literature. All of these precedents are of considerable interest, but their applicability is limited. Firstly, the studies concentrate on simple tasks or simplified domain concepts. Thus, the documented elicitation methods are not necessarily well suited to deal with the process of eliciting conceptual metaphors from conversations between musicians where the concepts under discussion may involve substantial 
complexity. Furthermore, there is limited discussion on the relative benefits or drawbacks of the elicitation methods used.

Drawing on the studies carried out by Antle et al. (2009b), Hurtienne at al. (2008) and Treglown (1999) and in contrast with the examples of eliciting image schemas and conceptual metaphors from music theory texts (Saslaw 1996, 1997-1998), we made the decision to focus upon the elicitation of conceptual metaphors from conversations between musicians. We posit that conversations are a fruitful source of conceptual metaphors as these may better reflect musicians' thought processes in practice in comparison with the more analytical descriptions provided in music theory texts. To that end, a series of three studies was carried out to elicit conceptual metaphors from conversations between musicians. In the following section, we contrast the approaches taken in the three studies and reflect on the relative benefits and drawbacks of each approach.

\section{OVERVIEW OF STUDIES}

The three studies explored various parameters including the impact of different study materials, task design and the domain knowledge and skill of the participants. In all cases, groups of participants were asked to work together to carry out tasks as part of the study. It was believed that collaboration would be conducive to encouraging detailed conversations from which a wealth of relevant conceptual metaphors could be elicited.

\subsection{Study 1 - Eliciting Conceptual Metaphors Using Musical Scores}

The first of the three studies explored the process of eliciting conceptual metaphors from conversations between highly skilled and experienced musicians discussing a short excerpt of music. This study and subsequent analysis of the results is discussed in detail in Wilkie et al. (2010), thus we only provide a brief overview here for the purposes of comparison.

\subsubsection{Study Design}

Three highly skilled and experienced musicians were recruited to take part in the study. The participants were provided with an excerpt from a musical score of a sacred motet for voices, strings and continuo written by Monteverdi. The participants were asked to review the excerpt and discuss the melodic and harmonic progressions, the interplay between the parts and how they felt about the excerpt.

\subsubsection{Study Results}

The discussion was audio recorded and transcribed for analysis. Using examples provided by other authors (e.g. Hurtienne 2007, Hurtienne and Blessing 2007, Hurtienne et al. 2008, Lakoff and Johnson 2003), the transcription was analysed to identify firstly the images schemas and secondly, the conceptual metaphors used by the participants while discussing the excerpt. A variety of conceptual metaphors were identified defining various aspects of music. Many of those identified were associated with structural aspects of music such as harmonic progression (e.g. HARMONIC PROGRESSION IS MOVEMENT ALONG A PATH), musical structure (e.g. A PIECE OF MUSIC IS CONSTRUCTED FROM A NUMBER OF PARTS) and pitch (e.g. HIGH PITCH IS UP/LOW PITCH IS DOWN).

Despite the encouraging results from this study, a number of limitations were recognised. Firstly, the study was limited with respect to the number of participants. Increasing the number of participants would provide more opportunities for additional relevant conceptual metaphors to be revealed. Further, all the participants were highly skilled and experienced musicians. Participants with more varied skills and experience may utilise additional or alternative conceptual metaphors to structure their understanding of musical concepts. Finally, only one short excerpt provided in musical score format was used in the study. An excerpt presented in an alternative format may have resulted in a different set of conceptual metaphors. To that end, two further studies were carried out to explore these aspects of study design. The design of the second and third studies along with a preliminary analysis of the results is briefly discussed in Wilkie et al. (2013). However, we include here a more detailed discussion of the results of these studies.

\subsection{Study 2 - Eliciting Conceptual Metaphors Through Words and Images}

In the second study, the process of eliciting conceptual metaphors through the use of word and image prompts was explored. As part of the design of this study, we attempted to address the limitations identified in the previous study. Namely, the number and skills of the participants and the number and genres of the excerpts of music used as part of the study materials. All of the six participants that took part in the second study held a musical qualification from graded examination to a $\mathrm{PhD}$ in a musical topic. A selection of audio recordings of ten musical excerpts from various genres including jazz, Baroque and folk and with various instrumentations was prepared for the participants to discuss.

\subsubsection{Study Design}

The study was split into two tasks. In the first task, a series of words associated with previously catalogued image schemas (Hurtienne and 
Blessing 2007) were chosen. For example "journey" was chosen to represent the SOURCEPATH-GOAL image schema while "forcing" was chosen to represent the COMPULSION image schema. The participants were split into three groups. Each group was provided with the set of words, and asked to use the words to describe the form and structure of a selection of the musical excerpts chosen at random. In the second task, a series of clip art images were chosen to represent image schemas. For example an image of a magnet was chosen to represent the ATTRACTION image schema while an image of a man holding a stop sign was chosen to represent the BLOCKAGE image schema. Similar to the first task, the groups of participants were asked to use the images to describe the form and structure of a selection of the musical excerpts chosen at random.

\subsubsection{Study Results}

Although the tasks generated some interesting discussions among the participants, the opportunities for reliably identifying relevant conceptual metaphors were limited. The use of words and images and lack of detailed directions appeared to encourage the participants to discuss the excerpts in more literal terms or use the prompts to place the excerpts within a social or historical context. For example, while discussing the excerpt of Bartok's Music for Strings, Percussion and Celesta, one participant commented that they could "use that as background music to a fight scene quite happily." Another participant chose an image of scales (intended to represent the BALANCE image schema) to describe an excerpt of a Baroque duet sonata commenting that the scales looked "oldfashioned or ornate". Although conceptual metaphors could arguably be extrapolated from such comments, the lack of reference to a particular musical concept or a more detailed description of the association made meant any identification of a conceptual metaphor would be speculative at best. Taking into account the comparatively limited opportunities to reliably identify relevant conceptual metaphors from the discussions, it was decided to undertake no further analysis.

\subsection{Study 3 Eliciting Conceptual Metaphors Using Musical Scores and Audio}

In the final study, the use of a mixture of musical scores, practical demonstrations and audio recordings to elicit relevant conceptual metaphors was explored. Again, we attempted to address the limitations identified in the first study by involving participants with varying musical backgrounds and using multiple musical excerpts. Seven participants were recruited to take part in the study, all of whom played at least one instrument or sang regularly.
The participants were asked to bring along an excerpt of a musical score of a piece of music they knew well to the study along with an instrument of their choice. (A piano was provided for keyboard players while singers were not required to bring an instrument.)

\subsubsection{Study Design}

The participants were split into three groups. The study was split into two tasks. In the first task, the participants were asked to take it in turns to describe aspects of the excerpt of music they brought with them such as the melody, harmony and rhythm. The participants were offered the opportunity to demonstrate the excerpt on their chosen instrument if they were comfortable doing so. In the second task, each group of participants was provided with a musical score and audio recording of a twentieth century quartet piece. Participants were asked to describe an aspect of the piece that interested them such as the melody, harmony or rhythm.

\subsubsection{Study Results}

The discussions among the participants were audio recorded and transcribed for analysis. Drawing on the process used to identify conceptual metaphors in the first study, the image schemas and conceptual metaphors used by the participants while discussing the musical excerpts were identified. A large number of conceptual metaphors were identified across the three study sessions reflecting musical aspects such as musical and harmonic structure, pitch and stylistic qualities. However, some of these (e.g. MUSICAL REPETITION and A PART IS MOVEMENT) were arguably high level. Table 1 below shows an extract from the analysis.

Table 1 - The most frequently identified conceptual metaphors across the three study sessions. Words used to identify the image schema are highlighted in bold text.

\begin{tabular}{|c|c|c|c|}
\hline $\begin{array}{c}\text { Conceptual } \\
\text { Metaphor }\end{array}$ & $\begin{array}{c}\text { No. of } \\
\text { Instances }\end{array}$ & $\begin{array}{c}\text { Associated } \\
\text { Image } \\
\text { Schema }\end{array}$ & $\begin{array}{c}\text { Example } \\
\text { Comment }\end{array}$ \\
\hline $\begin{array}{c}\text { A PIECE OF } \\
\text { NUSIC HAS A } \\
\text { NUBER OF } \\
\text { PARTS }\end{array}$ & 31 & $\begin{array}{c}\text { PART- } \\
\text { WHOLE }\end{array}$ & $\begin{array}{c}\text { “...see if it's } \\
\text { closely aligned } \\
\text { to the voice } \\
\text { part" }\end{array}$ \\
\hline $\begin{array}{c}\text { HIGH PITCH } \\
\text { IS UP/LOW } \\
\text { PITCH IS } \\
\text { DOWN }\end{array}$ & 33 & UP-DOWN & $\begin{array}{c}\text { “...and then they } \\
\text { go high" }\end{array}$ \\
\hline $\begin{array}{c}\text { A PIECE OF } \\
\text { MUSIC IS } \\
\text { MOVEMENT } \\
\text { ALONG A } \\
\text { PATH }\end{array}$ & 57 & SOURCE- & $\begin{array}{c}\text { "...it has...a } \\
\text { middle, } \\
\text { beginning and } \\
\text { end..." }\end{array}$ \\
\hline MUSICAL \\
REPETITION
\end{tabular}




\section{COMPARISON OF METHODS}

Across the three studies, a number of different approaches to eliciting conceptual metaphors and study parameters have been explored. These are summarised in table 2 below. Of all of the approaches taken, the use of musical scores was the most successful for the purposes of identifying relevant conceptual metaphors. However, the visual structure of a musical score showing musical notes contained within bars and staves emphasises and reifies containment and path relationships in comparison with other less-visual representation formats such as audio recordings. Although only two representation formats were considered in our studies, we posit that different representation formats will implicitly influence participants' conversations and thus the conceptual metaphors elicited.

With regards to the skill and experience of the participants, a review of the transcriptions of both studies one and three appears to indicate that a more detailed discussion of the harmonic structure of the musical excerpt took place in the first study when all of the participants were highly skilled and experienced. For example in the first study, seventeen instances of the conceptual metaphor HARMONIC PROGRESSION IS MOVEMENT ALONG A PATH were identified. In third study, only twenty-four instances of the same conceptual metaphor were identified across all three study sessions. However, the increased number of musical excerpts in the third study would have resulted in the participants spending less time discussing each excerpt potentially reducing the level of detail achieved. In addition, the analysis of the third study was undertaken using a refined version of the initial identification process used in the first study. These differences would have had some impact on the number and variety of conceptual metaphors elicited. Nevertheless, based on the number of additional participants in the third study, we had anticipated a bigger increase in the number of instances of this specific conceptual metaphor. Particularly when we consider that this conceptual metaphor had been identified or implicitly alluded to by other authors (e.g. Brower 2000, Saslaw 1996).

\section{DISCUSSION}

Through the comparison of the results of the three studies, we have identified some important considerations for the design of future studies to elicit relevant conceptual metaphors from conversations between domain experts. Firstly, we have highlighted the significance of choosing appropriate materials and giving the participants adequate direction. The use of word and image prompts in study two in combination with audio files and the lack of clear direction given to the participants led to very general discussions with limited references to complex musical concepts. In addition, we have highlighted the potential impact of the number of materials provided to the participants on the depth of relevant conceptual metaphors elicited. In the third study, the increased number of musical excerpts and subsequent reduction in opportunities to discuss the excerpts in detail may have been one of the factors that impacted on the lower than expected references to specific conceptual metaphors. Finally, we have highlighted the importance of considering the level of skills, background knowledge and experience of the participants. Taking into account these findings, we can make the following recommendations for the design of future studies. Firstly, in the domain of music, we recommend the use of musical scores as prompts. Musical scores reify and emphasise aspects of musical structure in contrast with other representation formats. Secondly, to avoid uncertainty, we recommend participants be given clear directions on which domain concepts should be discussed and to what level of detail. Finally, to ensure participants are comfortable articulating concepts, we recommend involving participants with high levels of skill and experience in the domain. Although these recommendations are drawn from studies carried out in the domain of music, we believe that they are equally valid in other domains where concepts are challenging for even the most experienced expert to conceptualise or articulate (e.g. graphic design or software development).

\section{CONCLUSION}

The purpose of this paper was to explore the advantages and disadvantages of different approaches to eliciting relevant conceptual metaphors from domain experts. This was achieved by contrasting the results of three previous studies carried out with the intention of eliciting relevant conceptual metaphors from discussions between musicians. Each of the studies took a different approach to eliciting relevant conceptual metaphors from conversations between domain experts, in this case, musicians. Drawing on the results of the three studies, we have provided a series of recommendations for the design of future studies. We suggest that future work may wish to consider the impact of utilising other musical notation formats (e.g. guitar tablature or figured bass) on the breadth and depth of conceptual metaphors elicited. Alternative directions could involve the analysis of any physical gestures made by the participants during the conversations for the purposes of illuminating the conceptual metaphor identification process. 
Table 2 - Summary of the various approaches to eliciting relevant conceptual metaphors and parameters explored in the three studies.

\begin{tabular}{|c|c|c|c|c|}
\hline Study & Participants & Music & $\begin{array}{c}\text { Supporting } \\
\text { Materials }\end{array}$ & Representation Format \\
\hline 1 & $\begin{array}{c}3-\text { all highly skilled and } \\
\text { experienced }\end{array}$ & 1 excerpt of a sacred motet & None & Musical score \\
\hline 2 & $\begin{array}{c}6 \text { - varying musical } \\
\text { backgrounds and levels of } \\
\text { experience }\end{array}$ & $\begin{array}{c}\text { Random selection of pre- } \\
\text { prepared excerpts in varying } \\
\text { genres }\end{array}$ & $\begin{array}{l}\text { Word and image } \\
\text { prompts }\end{array}$ & Audio recordings \\
\hline \multirow[t]{2}{*}{3} & \multirow{2}{*}{$\begin{array}{c}7 \text { - varying musical } \\
\text { backgrounds and levels of } \\
\text { experience }\end{array}$} & $\begin{array}{c}\text { Task } 1 \text { - Excerpts chosen by } \\
\text { participants }\end{array}$ & \multirow[t]{2}{*}{ None } & $\begin{array}{c}\text { Task } 1 \text { - Musical scores and optional } \\
\text { demonstrations }\end{array}$ \\
\hline & & $\begin{array}{l}\text { Task } 2 \text { - Excerpt of a } 20^{\text {th }} \\
\text { century quartet }\end{array}$ & & $\begin{array}{l}\text { Task } 2 \text { - Musical scores, audio } \\
\text { recordings and optional } \\
\text { demonstrations }\end{array}$ \\
\hline
\end{tabular}

\section{REFERENCES}

ANTLE, A.N., CORNESS, G. and DROUMEVA, M., 2009a. Human-computer-intuition? Exploring the cognitive basis for intuition in embodied interaction. International Journal of Arts and Technology, 2(3), pp. 235-254.

ANTLE, A.N., CORNESS, G. and DROUMEVA, M., 2009b. What the body knows: Exploring the benefits of embodied metaphors in hybrid physical digital environments. Interacting with Computers, 21(1), pp. 66-75.

BROWER, C., 2000. A cognitive theory of musical meaning. Journal of Music Theory, 44(2), pp. 323379.

HURTIENNE, J., 2007. ISCAT - Image Schema Database. Available at http://iscat.zmms.tuberlin.de:8080/iscat/. [Accessed February 2009].

HURTIENNE, J. and BLESSING, L., 2007. Design for Intuitive Use - Testing Image Schema Theory for User Interface Design, Proceedings of the 16th International Conference on Engineering Design, 2007, pp. 1-12.

HURTIENNE, J., ISRAEL, J.H. and WEBER, K., 2008. Cooking up Real World Business Applications Combining Physicality, Digitality, and Image Schemas, Proceedings of the 2nd International Conference on Tangible and Embedded Interaction, 2008, ACM, pp. 239-246.

LAKOFF, G. and JOHNSON, M., 2003. Metaphors We Live By. 2nd edn. London: The University of Chicago.

LAKOFF, G. and JOHNSON, M., 1999. Philosophy in the Flesh. New York: Basic Books.

LAKOFF, G. and NUNEZ, R.E., 2000. Where Mathematics Comes From. Basic Books.
LARSON, S., 1997-1998. Musical forces and melodic patterns. Theory and Practice, 22- 23, pp. 55-71.

SASLAW, J., 1997-1998. Life Forces: Conceptual Structures in Schenker's Free Composition and Schoenberg's The Musical Idea. Theory and Practice, 22-23, pp. 17-34.

SASLAW, J., 1996. Forces, Containers, and Paths: The Role of Body-Derived Image Schemas in the Conceptualization of Music. Journal of Music Theory, 40(2), pp. 217-243.

TREGLOWN, M., 1999. The role of metaphor in user interface design. Unpublished PhD Thesis, The Open University.

WILKIE, K., HOLLAND, S. and MULHOLLAND, P., 2013. Towards a participatory approach for interaction design based on conceptual metaphor theory: a case study from music interaction. In: S. HOLLAND, K. WILKIE, P. MULHOLLAND and A. SEAGO, eds, Music and Human-Computer Interaction. London: Springer, pp. 259-270.

WILKIE, K., HOLLAND, S. and MULHOLLAND, P., 2010. What Can the Language of Musicians Tell Us about Music Interaction Design? Computer Music Journal, 34(4), pp. 34-48.

ZBIKOWSKI, L.M., 1997. Conceptual Models and Cross-Domain Mapping: New Perspective on Theories of Music and Hierarchy. Journal of Music Theory, 41(2), pp. 193- 225. 